\title{
Chimpanzés possuem cultura? Questões para a antropologia sobre um tema "bom para pensar"
}

\author{
Eliane Sebeika Rapchan \\ Docente da Universidade Estadual de Maringá
}

RESUMO: O texto propõe uma reflexão sobre a crescente utilização da idéia de cultura, nos últimos anos, para definir alguns aspectos do comportamento de chimpanzés, considerando as características e os contextos, bem como as questôes que esse tipo de procedimento coloca para as ciências sociais, a partir de uma antropologia das idéias e do conhecimento.

PALAVRAS-CHAVE: culturas de chimpanzés, darwinismo, etologia, evolução/adaptação, relações natureza/cultura.

\section{Antropologia e biologia: relaçóes delicadas}

Os temas que aproximam antropologia e biologia são difíceis e delicados, particularmente para a antropologia cultural e social, devido à longa e trágica história dos desdobramentos de idéias que, ao tentar produzir definições para o humano (Chazan, 1995; Ingold, 1995), associaram determinantes físico-biológicos à vida social, problema discutido por autores como Comas (1970), Kuper (1994), Lévi-Strauss (1970), Poliakov (1970), Said (1990, 1995) e outros. Uma das conseqüências dessas idéias foi a produção de classificações determinísticas e etnocêntricas que 
dispuseram caçadores-coletores, hominídeos (Spencer, 1995), grandes símios (Blanckaert, 1995), populaçōes caiçaras, rurais e tribais, especialmente as africanas (Pieterse, 1995), em escalas inferiores aos europeus e norte-americanos urbanos, sustentando políticas imperialistas, eugenia, etnocídio, genocídio, segregação.

No entanto, isso não é justificativa para que antropólogos escapem das discussóes que afloram em diversas áreas das ciências naturais, inclusive, porque dados e questôes postos atualmente por elas dizem respeito, e muito, à antropologia cultural e social. Leve-se em conta, por exemplo, o fato de que pesquisadores que operam no campo das biociências, no estudo do comportamento, têm trabalhado com idéias tais como: cultura, consciência, relações sociais, poder ou tradição.

A adesão a influências evolucionistas pela antropologia e sociologia, entre a segunda metade do século XIX (Blanckaert, 1995) e início do século XX (Blanc, 1975), apesar de ter persistido de muitos modos por várias décadas (Kuper, 1996), constitui talvez o único paradigma integralmente descartado pela antropologia contemporânea (Oliveira, 1988, 1996, 1997). Por outro lado, como se sabe, Boas (cf. Lewis, 2001) e Malinowski (1978), através, e a partir, da adoção do método etnográfico, combateram eficientemente as atribuições de atraso e as explicações precipitadas sobre as diferenças humanas. Boas atacou o determinismo geográfico, as concepções de história universal e as comparaçôes entre artefatos culturais descontextualizados. Na medida em que a etnografia firmou-se como prática antropológica, mais subsídios foram fornecidos para o descarte das influências spencerianas (Stocking, 1997) .

Contudo, a partir de meados de 1970, a sociobiologia (Wilson, 1975; Ruse, 1983) e a noção de meme (Dawkins, 2001; Kuper, 2000), os estudos em comportamento animal, particularmente primatas (Fragaszy, 2003; Perry et al., 2003; Rodseth, Wrangham, Harrigan \& Smuts, 1991; Visalberghi \& Mcgrew, 1997; Whiten et al. 1999, 2001), a psicologia 
evolucionista (Barkow, 1992; Tooby \& Cosmides, 1992), a antropologia biológica (Henrich \& Mclreath, 2003), a antropologia cognitiva (Sperber, 1985) e mesmo algumas reflexôes no interior da antropologia social (Asquith, 1995; Durham, 2003; Ingold, 1996a; Kuper, 1994) reacenderam o debate sobre as fronteiras entre o biológico e o cultural. Tais abordagens têm, por assim dizer, "provocado" os cientistas sociais em seu exercício intelectual e no tratamento de fenômenos consensualmente considerados, até há pouco, exclusivamente humanos, produtos de relações humanas em toda sua extensão e, justamente por isso, objetos, por excelência, das humanidades. Mas o que uma observação mais cuidadosa dessa configuração pode revelar?

Por um lado, a legitimação do consenso, fora das ciências sociais, da centralidade das relaçóes entre humanos e com seu meio que conduziram a cultura e a sociedade a patamares que não podem ser ignorados. Por outro lado, um fator agregado ao primeiro, a crescente identificação da importância dos fenômenos grupais em espécies não-humanas que dependem fortemente de interaçóes entre a unidade e o coletivo para realizar-se plenamente. Ou seja, a adoção de perspectivas de que existem relaçôes consistentes entre capacidades cognitivas, dinâmica de grupo e vida coletiva (Dunbar, 2003).

A importância do aprendizado social para seres não-humanos não é descoberta recente. O antropólogo Ralph Linton (1936) mencionava já na década de 1930 a centralidade disso para os felinos. Porém, nas últimas décadas, é significativo o número de pesquisadores (Böesch \& Tomasello, 1998; Cavalli-Sforza, 2001; Hrdy, 2001; Mithen, 2002; Tooby \& Cosmides, 1992) que não são cientistas sociais, mas têm encarado cultura e sociedade como fatores fundamentais para a compreensão da evolução, no sentido darwiniano, apesar das dificuldades inerentes à abordagem do assunto (Skrzypczak, 1996). Mais do que isso, a experiência de qualquer animal não-humano em seu meio, ao longo de 
sua existência, tem adquirido uma crescente relevância, borrando definitivamente as fronteiras daquilo que é convencionalmente chamado de "inato" e de "adquirido"

Iniciativas que buscam refletir sobre consciência animal (Ades, 1997), aprendizado social (Böesch \& Tomasello, 1998), "culturas" não-humanas (Bonner, 1983; Henrich \& McElreath, 2003; Laland \& Hoppitt, 2003; McGrew, 1996; Whiten et al., 1999, 2001; Wrangham et al., 2001) e dinâmica das relaçóes entre grandes símios ou macacos (Mason \& Mendoza, 1993; De Waal, 2000) são bons exemplos. Esses estudos fundamentam-se em concepções segundo as quais são centrais a interação entre as características decorrentes da herança genética e do meio social onde afloram, desenvolvem-se e influenciam-se mutuamente (Tooby \& Cosmides, 1992), seja nos indivíduos, seja na coletividade (Henrich \& McElreath, 2003).

Essas abordagens não só escapam da visão posta pelas ciências sociais para a definição do humano, mas se pautam na possibilidade de esses processos serem poderosos fatores seletivos e adaptativos, no sentido evolutivo (Alvard, 2003). Assim, advogam os pesquisadores, tais características não seriam exclusivamente humanas (Foley, 1993), mas seriam manifestas nas próprias singularidades noutras espécies (Darwin, 2001, 1998), inclusive em grandes símios (Böesch \& Tomasello, 1998; CavalliSforza, 2001) e nos hominídeos (Joulian, 1996; Mithen, 2002).

Contudo, existe hoje uma significativa diferença nas relações entre as idéias de evolução, de sociedade e de cultura estabelecidas há um século e as atuais. Como se verá, mesmo propostas fundadas em duras críticas às ciências sociais com vistas a integrá-las às teorias evolucionistas (Alvard, 2003; Tooby \& Cosmides, 1992) não se sustentam sobre perspectivas mecanicistas ou etnocêntricas, são, pelo contrário, sutis e sofisticadas. Impóem-se cada vez mais nas biociências concepções de que a vida social e a cultura são produtos de capacidades cognitivas herdadas 
que se desenvolvem entre seres que vivem em unidades coletivas complexas (Dunbar, 2003), de modo que o adquirido e a experiência constituem aspectos fundamentais para a compreensão de sua dinâmica de vida (Kuper, 1994; Rodseth, Wrangham, Harrigan \& Smuts, 1991).

Assim, ao mesmo tempo em que fenômenos de ordem social e cultural adquirem legitimidade e passam a ser correntes nas biociências, as concepções do que sejam cultura e sociedade escapam ao controle dos cientistas sociais, sendo submetidas a outros parâmetros. Isso quer dizer que, ao adotar as definições de cultura e tradição como válidas para chimpanzés (Wrangham et al., 2001; Whiten et al., 1999, 2001), para outros grandes símios e macacos (Pavelka, 2002; Perry et al., 2003; Visalberghi \& McGrew, 1997) e mesmo para outras espécies (Laland \& Hoppitt, 2003), pesquisadores produzem aplicaçōes da idéia de cultura ignoradas pela antropologia de ênfase puramente sociocultural e, mais do que isso, reformulam-na, não só tentando torná-la válida para explicar o comportamento de seres não-humanos, mas também reinventando sua aplicabilidade ao humano.

Ao mesmo tempo, vale ressaltar, manifesta-se entre muitos cientistas naturais uma sensibilidade explícita quanto às repercussões éticas e políticas de suas abordagens, principalmente, no combate a idéias que deram ou possam vir a dar sustentação ao racismo, ao etnocentrismo, ao chauvinismo ou à xenofobia (Cavalli-Sforza, 2001; Corbey \& Theynissen, 1995; Hrdy, 2001; Wrangham \& Peterson, 1996).

São comuns, em trabalhos de antropologia biológica ou etnoarqueologia, por exemplo, referências a dados etnográficos sobre populações caçadoras-coletoras vivas por uma perspectiva totalmente antietnocêntrica. Ou seja, elas são tomadas como culturas contemporâneas cujo desenvolvimento é tão complexo e moderno quanto o de qualquer outra (Hrdy, 2001; Mithen, 2002). 
Em contrapartida, no horizonte das ciências sociais, temos a turbulência produzida pelas pesquisas sobre grandes símios que, no mínimo, se tornaram temas "bons para pensar". O uso de idéias como cultura, poder, relações sociopolíticas ou tradição é cada vez mais corrente para explicar fenômenos comportamentais não-humanos, ao mesmo tempo em que antropólogos, biólogos, etólogos ou psicólogos evolutivos questionam a validade das definições dessas idéias pela antropologia sociocultural, por considerá-las pouco precisas (Alvard, 2003) ou por não reconhecerem a legitimidade de seus pressupostos (Barkow et al., 1992).

Ao mesmo tempo, a carência de reflexóes contemporâneas sobre questôes postas pela antropologia para a biologia e vice-versa, bem como as implicaçōes metodológicas e teóricas advindas daí, chama a atenção e é, de certo modo, desoladora, tendo sido assinalada, por Kuper (1994, p. viii), Ingold (1996), Vayda (1996) e Sperber (1985). Kuper pergunta-se se somos todos darwinistas, inclusive os antropólogos, e propõe o reconhecimento da existência do problema bem como o diálogo da antropologia social com idéias e resultados atuais das pesquisas em ciências biológicas.

Ingold (1996, p. 112-13), por sua vez, avalia se antropólogos, em seu exercício intelectual, têm de, necessariamente, acatar paradigmas dicotômicos e optar pela "animalidade" ou pela "humanidade", por "um mundo" ou por "vários mundos", pela "natureza" ou pela "cultura", pelo "dado" ou pelo "construído" ou, por outro lado, se nossa cognição orienta-se não a partir de dicotomias, mas de uma matriz relacional, optando pela segunda via. Sperber (1985) engrossa as fileiras dos que defendem uma maior aproximação entre ciências naturais e ciências sociais, de modo que afirmaçóes da antropologia venham a dialogar e levar em consideração conceitos e descobertas gerados a partir da teoria evolucionista (Tooby \& Cosmides, 1992). O alerta desses autores aponta para a emergência de um novo ponto crítico tanto para as ciências 
sociais e humanas quanto para as, por assim dizer, ciências da vida (cf. Queiroz, 1998).

Em The Chosen Primate (1994), Kuper defende o avanço do diálogo entre antropologia e biologia, considerando que as pesquisas em genética podem revelar algo sobre as raízes do comportamento humano (1994, p. 11). Segundo ele, talvez até agentes e processos da evolução cultural possam ser decodificados, e a genética possa vir a reescrever as ciências humanas (ibid.). No entanto, adverte o autor, mesmo considerando o avanço dessas trocas interdisciplinares, objetos culturais e vida social são históricos, por isso é extremamente improvável que sejam transmitidos, tal como se manifestam, pela via da genética (ibid.). Assim, defende Kuper, é preciso lidar com o fato de que somos produto de uma dupla herança - a "genética" e a "adquirida e repassada" -, e uma não pode determinar a outra, em sentido estrito, nem sobrepujá-la (ibid.).

Essa "dupla herança” ou, como prefere Ingold (1996), a necessidade de abandonar a adesão essencialista a um dos lados dos já mencionados "paradigmas dicotômicos", somada às questões postas pela genética das populações (Cavalli-Sforza, 2001) e pela paleontologia contemporânea (Corbey, 1995) expressam a necessidade de uma abordagem multidisciplinar de questôes referentes ao que foi classicamente denominado "relações natureza/cultura”. Isso não quer dizer que apontem para um esvaziamento das ciências sociais, nem para uma guerra de trincheiras em que cada disciplina deva alinhar-se tomando outras como ameaças mortais. Ao contrário, indicam contribuições que o diálogo entre disciplinas pode trazer ao debate, mesmo que a partir de diferentes pontos de vista e de partida.

No Brasil, Durham (2003) foi uma das primeiras a tocar no assunto, procurando integrar reflexôes da antropologia sociocultural e da psicanálise aos resultados de pesquisas sobre comportamento de chimpanzés, particularmente no que se refere às emoções (Durham, 2003, p. 87). 
A proposta da autora é rever o que ela chama de "clássica oposição natureza/cultura" a partir da seguinte premissa: se humanos são distintos dos animais nos planos de consciência, raciocínio, linguagem e instrumental simbólico, partilhamos com eles componentes emocionais, fundamentais para a constituição e preservação dos grupos sociais.

Em direção convergente, Lévi-Strauss demonstrou, em entrevista a Massenzio (2001), não ignorar os rumos das atuais pesquisas em genética das populaçôes, mantendo a coerência com suas idéias acerca das íntimas relações entre antropologia e biologia (Lévi-Strauss, 1993, p. 26). Outra faceta desse contexto são as pesquisas que Lieberman (1989) tem conduzido com o intuito de avaliar o grau de aceitação dos conceitos da sociobiologia no interior da antropologia cultural norte-americana.

As pesquisas sobre comportamento de grandes símios expressam outras faces, veladas ou explícitas, das relações entre antropologia sociocultural e biociências. Apesar de os estudos sobre comportamento animal, inclusive chimpanzés, promovidos por Robert M. Yerkes e Wolfgang Köhler datarem de 1910-1920, ocorreram profundas mudanças entre as décadas de 1960 e 1970 (Rodman, 1999), observáveis na construção do objeto de pesquisa e na adoção de procedimentos de campo. A pesquisa intensa e continuada sobre um determinado grupo de chimpanzés, a utilização de nomes para identificação de cada indivíduo, a observação das dinâmicas coletivas diante das condutas individuais e vice-versa, a observação da variabilidade dos laços parentais, a dinâmica do status no interior do grupo e o registro de histórias de vida, procedimentos adotados por Irwing De Vore, Jane Goodall e outros, que geraram à época repúdio na comunidade de primatólogos (Goodall, 1991), não são, em absoluto, estranhos aos antropólogos socioculturais.

Assim como os antropólogos, e devido provavelmente ao convívio intenso com os grandes símios, pesquisadores penetram em outros mundos, como pode ser observado nos registros de Fouts e Mills (1998), 
Goodall (2000, 1991, 1965), De Vore (1965) e De Waal (2000). Há freqüentes manifestaçōes de dilemas éticos quanto ao manejo desses seres (Buning, 1995; Dukelow, 1999; Crocket et al.,1999; Fouts \& Mills, 1998), bem como esforços políticos e acadêmicos constantes no sentido de estabelecer "pontes" entre humanos e outros primatas (Goodall, 1991; Cavalieri \& Singer, 1995; Spruit, 1995), no sentido de protegê-los.

\section{Culturas de chimpanzés: definiçōes e questóes}

Diante dessa confluência de elementos, emerge o debate sobre a existência de "culturas de chimpanzés". O uso crescente da expressão "cultura", fora dos terrenos da antropologia social e cultural, em pesquisas sobre o comportamento de chimpanzés, mobiliza, atualmente, muitos estudiosos em favor do estabelecimento de termos comuns, da troca de dados e da sistematização coletiva das observações (Heltne, 2001; Wrangham et al., 2001; Whiten et al., 1999, 2001). Isso pode ser observado na coletânea Chimpanzee Culture (Wrangham et al., 2001), resultado do último de três congressos internacionais que reuniram estudiosos do comportamento de chimpanzés, patrocinados pela Academia de Ciências de Chicago (Whiten et al., 1999).

Tais resultados têm o potencial de impactar as representações da natureza e, ao mesmo tempo, promover alteraçóes nas relaçôes entre as disciplinas envolvidas no problema, trazendo contribuiçōes para o debate sobre as relações natureza/cultura ou, ainda, para a redefinição das fronteiras do que se entende por "humano" e "não-humano" (Joulian, 1995; Pieterse, 1995; Rapchan, 2004).

Desse modo, é urgente refletir sobre os usos e sentidos que a idéia de cultura adquire entre pesquisadores do comportamento de chimpanzés. É preciso perguntar até que ponto ela opera nos termos da antropologia 
sociocultural ou se segue lógicas totalmente próprias e distintas. Se a cultura de chimpanzés for algo próprio desses grandes símios, trata-se de conhecimentos independentes que, a rigor, possuem apenas o mesmo nome. Caso contrário, diz respeito às práticas dos antropólogos sociais e culturais e, então, a antropologia deve manifestar-se. Um exame rápido permite perceber que a idéia de cultura para a etologia contempla os grandes símios, congrega vários seres sociais e se pretende válida para os humanos e, a partir daí, colocam-se outros problemas.

Assim, caso os etólogos apresentem argumentos convincentes em favor da existência de culturas entre chimpanzés, uma das conseqüências para os antropólogos sociais e culturais seria a necessidade de repensar os parâmetros daquilo que chamamos "alteridade" (Pieterse, 1995, p. 348; Rapchan, 2004; Rooijakkers, 1995, p. 327). Por outro lado, se chimpanzés possuem efetivamente algo que se aproxime à cultura, no sentido antropológico, as contribuições dos antropólogos a esse tipo de pesquisa seriam indispensáveis, dado o conhecimento e a reflexão acumulados nos trabalhos de campo e na produção de etnografias somados ao arcabouço analítico e teórico produzido a partir dessa experiência (Tuttle, 2001).

Em outras palavras, caso a idéia de cultura seja válida para os seres não-humanos, certamente há muito que se discutir quanto a isso, não só as ciências sociais, mas também as ciências biológicas, terão de rever seus paradigmas, pois certamente o papel das primeiras nesse processo não se restringiria ao fornecimento de nomes para fenômenos, tais como "cultura", "tradição" ou "organização social". 
Revista de Antropologia, São Paulo, USP, 2005, v. 48 No 1.

\section{Darwin, antropologia e as relações natureza/cultura}

Dentre os estudos sobre comportamento animal, pesquisas voltadas para as "culturas de chimpanzés" não são iniciativa isolada. Há vários trabalhos pautados na importância da experiência, do "adquirido" na modulação da vida, sobre várias espécies. Inúmeras facetas das relações natureza/cultura têm sido pedra-de-toque para pesquisadores envolvidos com grandes símios e macacos (Visalberghi \& McGrew, 1997), ou mesmo pássaros (Laland \& Hoppitt, 2003), elefantes e cetáceos (Rendell \& Whitehead, 2001), para os quais também têm-se cogitado a existência de cultura e/ou a transmissão de tradições (Fragaszy, 2003), fatores tidos como centrais para o sucesso de sua evolução e adaptação.

No caso dos grandes símios, esse ponto de vista fundamenta-se principalmente em registros produzidos nas últimas quatro décadas e nos estudos comparativos entre espécies. Além dos chimpanzés e bonobos, há trabalhos sobre "tradições" entre os orangotangos (Schaik et al., 2003) e o uso de ferramentas e as práticas de forrageamento entre gorilas e macacos Cebus (Perry et al., 2003), estes últimos comuns na América Latina. Os primatólogos têm definido como tradiçôes ontogeneticamente adquiridas (Tomasello, 2001, p. 301) os comportamentos de indivíduos, resultantes da interação com seu meio natural e social, que são repassados por meio de gerações (Fragaszy, 2003; Nishida, 1987).

Tais pesquisadores não pretendem atribuir aos chimpanzés um lugar especial devido à sua proximidade e semelhança com os humanos, de modo a constituir outra "espécie única" (Foley, 1993). Pelo contrário, sua intenção é sobrepujar concepçôes pautadas na singularidade humana absoluta, aproximando-a, tanto quanto possível, dos grandes símios e de outros animais sociais inteligentes a partir do aprofundamento das pesquisas sobre seus comportamentos. 
O debate sobre culturas de chimpanzés está na base desse processo, que pretende influenciar os parâmetros biológicos da evolução, dado que, como foi exaustivamente mencionado, é pautado na relevância da experiência, como já apontava Linton (1936), e não apenas na herança genética, como central para a seleção e adaptação, em particular, para as espécies consideradas capazes de produzir "cultura" (Böesch \& Tomasello, 1998). Essa abordagem é conhecida como co-evolução gene-cultura (Alvard, 2003) ou fenogenética construtivista (Foladori, 2000). Para a antropologia, por outro lado, todo o fundamento da vida social assenta-se exclusivamente em sua produção e reprodução por seus membros. A cultura produz os sujeitos, e eles são produzidos por ela, não havendo qualquer mediação de ordem biológica nesse processo. Esse fundamento é resultado direto, entre outras coisas, dos embates entre Boas e Leslie White (Kuper, 1994; Lewis, 2001).

Por ora, nos trabalhos em comportamento animal sob o enfoque da cultura, e mencionando apenas os dirigidos aos chimpanzés (Brosnan \& De Waal, 2003; De Waal, 2001a; Goodall, 2000; Hrdy, 2001; McGrew, 2001a, 2001b; Nishida, 2001, 1987; Rumbaugh et al., 2001; Tomasello, 2001; Whithen et al., 1999; Wrangham et al., 2001; Wrangham \& Peterson, 1996; Whrangham \& Huffman, 1994), predominam abordagens "abertas" e muito distantes de concepçôes pautadas em modelos orientados para determinações genéticas. Na maior parte dos casos, aliás, "inato" e "adquirido" não são domínios estanques, de modo que a manifestação do primeiro se imponha e anule o segundo. Pelo contrário, pesquisadores apresentam dados sobre aprendizado, inventividade, variabilidade de comportamento, transmissão e reprodução de condutas observados a partir da dinâmica comportamental dos casos estudados.

Os resultados sobre variabilidade de comportamentos entre grupos, por sua vez, não estão restritos à consonância com o meio ecológi- 
co: apontam diferenças de comportamento em hábitats semelhantes (Wrangham et al., 2001). Identificam e analisam interações pelas chaves da aliança e do conflito (Waal, 2000), observando o papel do status e das vantagens adquiridas (Wrangham \& Peterson, 1996), a dissimulação diante dos mais fortes, as reações diante do inesperado e o repasse intergeracional de posições sociais (Hrdy, 2001; Goodall, 1999) e do conhecimento adquirido (Böesch \& Tomasello, 1998). Tudo isso é promovido pela "tradição" (Nishida, 1987), nem herança genética nem comportamento são concebidos como pontos cegos e fixos.

Nos estudos sobre comportamento, parte-se da observação e do registro dos fenômenos, passando à análise do material, considerando a centralidade da experiência, e à reflexão teórica. Relações entre herança e experiência são concebidas como processos dinâmicos, interativos e não determinísticos.

Contudo, não foi sempre assim. Segundo Skrzypczak (1996, p. 81), a etologia, desde suas origens, debate-se entre dois tipos de explicação. Konrad Lörenz concentrou-se sobre os comportamentos característicos das espécies, considerando que sua generalidade na população seria o indício de sua determinação genética, mesmo quando sua manifestação depende de estímulos externos. Nikolaas Tinbergen, por sua vez, definiu o aprendizado como modus operandi do comportamento. Ambas têm, atualmente, apresentado tendência a aproximar-se. No entanto, conforme ainda Skrzypczak, discutir esse processo consiste em enfrentar três grandes dificuldades: "a grande complexidade de qualquer comportamento, a dificuldade de experimentação, as controvérsias quanto à definição de instinto" (ibid.).

Desse modo, se o inato nunca é descartado nas abordagens sobre culturas de chimpanzés, é importante avaliar como se dá sua participação na constituição desse conhecimento. O “instinto", para os etólogos, pode assumir papéis mais determinantes ou mais relacionais na definição dos 
seres vivos, de acordo com tendências variadas no interior do debate. Contudo, a pluralidade de sentidos que assume é uma característica real. Para que se tenha uma idéia, Bateson (2002) elaborou uma lista dos usos científicos do termo instinto, não necessariamente dependentes entre si, mas cujos sentidos podem operar de modo cumulativo. A abrangência é tal que pode até se equiparar à variabilidade dos sentidos de cultura na tradição antropológica. Conforme o autor, instinto pode ser:

(...) present at the birth (or at a particular stage of development), not learned, developed before it can be used, unchanged once developed, shared by all members of the species (or at least of the same sex and age), organized into a distinct behavioral system (such as foraging), served by a distinct neural module, adapted during evolution, and differences among individuals that are due to their possession of different genes. (Bateson, 2002, p. 2.212)

Assim, enquanto uma das críticas dirigidas às ciências sociais pelas biociências refere-se à condição multifacetada da noção antropológica de cultura (Alvard, 2003; Henrich \& McElreath, 2003; Tooby \& Cosmides, 1992), a idéia de "instinto" permanece, do mesmo modo, plural, abrangente e imprecisa.

Ainda na direção dos desafios que os etólogos precisam enfrentar, Gould (1999, p. 238-9) observa que erros podem ocorrer no estabelecimento de analogias entre o comportamento humano e de outros animais. A questão é que comportamentos análogos, do ponto de vista do fenômeno, podem não ser homólogos, ou seja, podem não possuir estruturas semelhantes, o que indica descendência e constituição genética distintas, no sentido evolutivo. Comportamentos análogos podem ser semelhantes, mas ter sido produzidos por desenvolvimentos independentes. Qual a validade dessa observação quando se faz comparações 
entre comportamentos de chimpanzés e humanos, no que se refere à existência de cultura?

$\mathrm{O}$ que se observa é que, à medida que pesquisas avançam e identificam uma grande semelhança entre os DNAs humano e dos chimpanzés (Goodman, 1999), e a paleontologia levanta indícios ecológicos e anatômicos que reforçam o pressuposto de que chimpanzés e hominídeos tiveram um ancestral comum e partilham muitas estruturas em sua constituição (Mithen, 2002; Wrangham \& Peterson, 1998), os estudos sobre comportamento de chimpanzés trazem dados e questões que procuram dar sustentação à existência de continuidades entre grandes símios e humanos não apenas quanto a traços visíveis, herdados geneticamente, mas também em suas habilidades de imitar, aprender, observar, adquirir por experiência, inventar e/ou ensinar aos outros, advindas do convívio social.

\section{Do comportamento animal às culturas de chimpanzés}

Em outro artigo (Rapchan, 2004), fiz breve recuperação de eventos relacionados às pesquisas sobre comportamento de chimpanzés, que serão retomados aqui. Ao observar a trajetória dos estudos modernos em antropologia e primatologia, o que primeiro chama atenção são alguns paralelos entre a história do interesse ocidental por primatas não-humanos (Asquith, 1995; Ohnuki-Tierney, 1995) e o estudo sistemático de culturas humanas: ambas surgiram em períodos próximos, transformaram profundamente as concepções sobre seus objetos a partir do desenvolvimento das pesquisas de campo e revolucionaram seus pressupostos teóricos na medida em que os resultados de trabalhos aprofundados e prolongados foram sendo incorporados às reflexôes de cada disciplina. 
$\mathrm{Na}$ Antigüidade clássica e durante a Idade Média, o conhecimento do Ocidente sobre primatas submeteu-se à classificação de Aristóteles (Spencer, 1995, p. 13), restrita ao mundo então conhecido, e só se ampliou a partir do estabelecimento do domínio europeu em outros continentes. Entre os séculos XVI e XVII, paralelamente às grandes navegaçôes, surgiram vários novos animais no horizonte do conhecimento zoológico do Velho Mundo. Os primeiros registros desses contatos foram feitos por viajantes cujas narrativas misturavam-se e enriqueciamse com crenças locais (Dougherty, 1995, p. 64). O conhecimento formal sobre primatas surgiu apenas no século XVII (Spencer, 1995, p. 13-14) quando o primeiro chimpanzé foi visto na Europa (Asquith, 1995, p. 310) e foram feitas descrições de primeira mão por médicos interessados em anatomia comparada com humanos (Dougherty, 1995, p. 64).

Entre o início do século XIX e as primeiras décadas do século XX, chimpanzés, gorilas, orangotangos e povos não-europeus foram observados em seus hábitats originais por missionários, naturalistas, viajantes, cientistas, exploradores e caçadores e, inclusive, por muitos que exerciam simultaneamente mais de uma função. Eles foram responsáveis pelos primeiros relatos, produzidos na África, que atravessaram o Atlântico e dali remeteram representantes de chimpanzés para serem examinados por cientistas da América e Europa (Reynolds \& Reynolds, 1965, p. 394-95). De modo semelhante, membros de povos indígenas foram enviados de todos os cantos para feiras e exposições organizadas nas regiōes tidas como civilizadas do planeta (Schwarcz, 1993).

Poliakov (1974) e Laurent (1995) apresentam substanciosos relatos das analogias construídas entre povos não-europeus ou camponeses e primatas não-humanos, a partir da atribuição ou identificação de semelhanças anatômicas ou fisiológicas, por naturalistas e cientistas, entre o século XVII e início do XX. Como expresso por ambos os autores, antes do advento da antropologia e da primatologia, o discurso sobre po- 
pulações tribais e grandes símios é, como bem afirma Nash (1995), um bestiário, recheado de monstruosidades e monstros - para primatas nãohumanos, ver Nash (1995, p. 64).

A partir do século XX, tanto na primatologia quanto na antropologia, a permanência prolongada em campo foi uma prática que se sedimentou aos poucos e foi responsável por reformulaçôes profundas do objeto, a partir da obtenção de dados novos e resultados inesperados da interação dos pesquisadores com os seres estudados. Os registros de Garner em 1896 são considerados a primeira tentativa de estudo em hábitats originais sobre chimpanzés e gorilas (Reynolds \& Reynolds, 1965, p. 394), mas o primeiro relatório produzido a partir de um estudo de campo mais prolongado (49 dias) é atribuído a Nissen, pesquisador do Yerkes Laboratory, pelo trabalho realizado na África Oriental, em 1931 (Reynolds \& Reynolds, 1965, p. 395).

O chamado "período moderno" do estudo do comportamento de chimpanzés inicia-se na década de 1950 , caracterizando-se por uma crescente expansão dos períodos de observação cada vez mais minuciosa (De Vore, 1965). Entretanto, estudos enfocando comportamento coletivo só surgiram na década seguinte (Reynolds \& Reynolds, 1965, p. 395).

Entre 1960 e 1970, vieram a público os primeiros resultados de estudos sobre chimpanzés em seus hábitats africanos originais. Jane Goodall no Parque Nacional de Gombe na Tanzânia desde 1960, Toshisada Nishida no Paque Nacional das Montanhas Mahale desde 1965, e Chirstophe e Hedwige Böesch na Floresta de Taï na Costa do Marfim desde 1976 foram os precursores dos três projetos de pesquisa sobre o comportamento de chimpanzés que acumulam o maior tempo de observação contínua sobre indivíduos conhecidos (Goodall, 2001, p. xv-xvii). A trajetória de Diane Fossey (1983), que se tornou popular com o filme que, no Brasil, recebeu o nome de $A$ montanha dos gorilas, soma-se aos estudos sobre chimpanzés. 
Contemporâneo a Biruté Galdikas, Diane Fossey e Jane Goodall, que iniciaram suas pesquisas através de Louis Leakey (Fossey, 1983; Goodall, 1991), o então assistente da cadeira de Antropologia Social Irwing De Vore (1965) foi enviado a campo pelo arqueólogo Sherwood Washburn (Kuper, 1994), para desenvolver pesquisa e registro sobre comportamento de babuínos africanos, segundo os padrōes da prática etnográfica. Todos os quatro partilhavam, então, uma total inexperiência nos estudos sobre grandes símios ou macacos (De Vore, 1965; Fossey, 1983; Jahme, 2001; Goodall, 1991, 2000).

Washburn pretendia efetuar comparaçóes entre populaçóes caçadoras-coletoras contemporâneas, ancestrais humanos e primatas sociais não-humanos, no plano da vida coletiva, segundo um viés evolucionista (Kuper, 1994), e tinha expectativas de que um antropólogo social fosse mais apto para "captar" as relações entre babuínos, pois considerava que biólogos e psicólogos, então praticantes da primatologia, tendiam a enfatizar aspectos isolados do comportamento, como forrageamento, condições ecológicas ou cuidado materno, impedindo a apreensão da vida social do grupo (Kuper, 1994). Talvez o intuito de Washburn fosse aproximar a pesquisa daquilo que Mauss (1974) chamou de "totalidade" nas sociedades humanas, questão que será retomada adiante.

Lévi-Strauss acompanhou esses acontecimentos e dirigiu críticas à comparação entre hominídeos e populaçôes caçadoras-coletoras contemporâneas, no plano da cultura (Kuper, 1994). Seu texto "A noção de arcaísmo em etnologia" (Lévi-Strauss, 1989a) demonstra que qualquer cultura que nos seja contemporânea não pode, por definição, ser arcaica. Apesar disso, a abordagem dos primatas como seres sociais e a adoção do trabalho de campo prolongado sedimentaram-se na etologia. As comparaçōes interespecíficas continuam, mas seus pesquisadores abandonaram sensivelmente o etnocentrismo (Hrdy, 2001; Mithen, 2002). 
Por outro lado, apesar do atual consenso quanto à importância do trabalho de campo contínuo e prolongado nos estudos sobre comportamento de chimpanzés, desdobramentos relativos aos procedimentos e à maneira de apresentar os dados descreveram outras trajetórias. O pioneirismo de Goodall e a ausência de qualquer formação acadêmica prévia (Goodall, 1991) contribuíram para produzir um "estilo" de pesquisa que coaduna com o de uma certa geração de pesquisadores, como Altman e De Vore (Rodman, 1999, p. 314). Permeável a influências da antropologia, esse estilo quase não produziu adeptos entre os etólogos e primatólogos de geraçôes posteriores, que preferiram adotar os parâmetros da ecologia comportamental e da sociobiologia (Rodman, 1999, p. 314).

A sensibilidade, inteligência e tenacidade de Goodall foram responsáveis pelas primeiras observações de "caráter" etnográfico sobre contato com chimpanzés livres, ao mesmo tempo, o modo como registrou os fenômenos observados e elegantemente expressou suas reflexões e experiências (Goodall, 2000, 1991) tornam seus artigos e livros imensamente familiares ao leitor antropólogo. O irônico é que se, de um lado, a leitura de seus relatos remete, facilmente, qualquer antropólogo a Boas (1940) ou Malinowski (1978), de outro, apesar do enorme respeito que Goodall possui entre os primatólogos, é fácil constatar que seu modo de fazer pesquisa não recebeu muitas adesões.

Contudo, há algo mais a observar quanto à prática etnográfica no interior da primatologia. Pesquisadores proeminentes na área, como McGrew (1998, p. 317), têm utilizado a expressão "ethnography of chimpanzees" para referir-se a trabalhos orientados para a abordagem das culturas de chimpanzés, com a justificativa de que, já que tratam de culturas, são, conseqüentemente, etnografias. É fácil para qualquer antropólogo sociocultural discordar do autor, considerando que a maioria dos traba- 
lhos sobre comportamento de chimpanzés não se encaixa em qualquer definição mínima de etnografia no sentido antropológico, mas não se pode negar que tal iniciativa está certamente relacionada a esforços em dar sentido para os dados levantados pelas pesquisas e à convicção de que "cultura" é um termo apropriado para caracterizar determinados aspectos do comportamento de chimpanzés. Daí, falar em etnografia pode, aos olhos dos primatólogos, aproximar os fenômenos relacionados a humanos e chimpanzés.

Evidentemente, do mesmo modo que há debates na antropologia sobre a legitimidade na produção do discurso etnográfico por outras disciplinas, há discussões entre pesquisadores do comportamento animal sobre a validade da adoção de procedimentos que considerem as interações entre pesquisadores e primatas não-humanos dados relevantes para as pesquisas (Altmann apud Hrdy, 2001), o que remete a concepções de objetividade pautadas em princípios de neutralidade. Esse é outro problema a ser enfrentado no âmbito das pesquisas sobre comportamento animal.

Desde a origem da disciplina (Lorenz, 1995, p. 127), etólogos têm pensado sobre riscos e vantagens da humanização do comportamento animal (Hrdy, 2001; Mitchell \& Hamm, 1997). Donald O. Hebb (apud Mitchell \& Hamm, 1997), em 1940, já defendia o uso de terminologia psicológica para descrever o comportamento animal, e pesquisadores como Ades (1997), Laland e Hoppitt (2003) e Mithen (2002) têm se perguntado se, quando humanos estudam comportamento animal, é possível escapar disso ou se, pelo contrário, a antropomorfização do comportamento de outros seres faz parte de nossos mecanismos cognitivos. A lembrança de Lévi-Strauss (1989b), para quem o mundo conhecido (natural e social) de qualquer sociedade é a parcela do circundante que "faz sentido", não é de modo algum aleatória. Basta observar as distinçōes relevantes, associadas às culturas, na abordagem 
dos grandes símios e macacos no Japão e no Ocidente, e manifestas na arte, ciência, cultura popular e filosofia produzidas por ambas as tradições (Asquith, 1995).

Desdobramentos contemporâneos da perspectiva lévistraussiana, no interior da antropologia social, remetem aos debates entre Philippe Descola e Dan Sperber acerca de diferentes leituras do estruturalismo, em particular quanto às relaçôes natureza/cultura. Sperber (1985), conhecido atualmente como um antropólogo cognitivista, tem sido parceiro intelectual constante de uma corrente da psicologia evolucionista (Tooby \& Cosmides, 1992, p. 119). Sperber (1996) critica a tese da autonomia ontológica da cultura que rejeita tanto os fatos biológicos quanto os psicológicos. Descola (1992, 2001), em contrapartida, busca na análise da diversidade de sistemas simbólicos de populações ou regiōes específicas, relacionando seus sistemas de pensamento à sua organização social e à natureza culturalmente reconhecida. Uma das interpretações possíveis é que os trabalhos de Sperber e Descola podem ser metáforas do dilema que se manifestou em toda a história da antropologia, de modo particularmente agudo no estruturalismo francês, entre os aspectos universais do homem enquanto espécie e os aspectos locais referidos à diversidade das culturas humanas, questões que não estão isoladas do que foi apresentado até aqui.

Tudo isso está relacionado, de algum modo, ao acúmulo, desde a década de 1960, de registros sobre o comportamento de chimpanzés em seus hábitats africanos originais, que têm trazido informaçôes capazes de abalar categorias de pensamento bem estabelecidas. Parece ir longe a reação de espanto de Leakey, o famoso paleontólogo, quando afirmou, diante dos relatos de Goodall sobre o uso de ferramentas por chimpanzés: "Se você estiver certa, ou alteramos o que entedemos por ferramentas ou modificamos nosso entendimento sobre o que é um ser humano" (Goodall, 1991). 
Naquela década, além do registro do uso de ferramentas, Goodall (1991) foi também pioneira na divulgação de dados sobre o consumo de carne por chimpanzés mas, do mesmo modo que seus antecessores, não identificou formalmente estruturas organizacionais nos grupos que estudou, apesar de ter analisado detalhadamente a diferenciação sexual, as relações mãe/filhos, a hierarquia e a luta para ocupar posiçōes de mando que constituem, claramente, elementos básicos da organização social.

Foi Nishida quem propôs um modelo para a sociedade chimpanzé que chamou de "unidade-grupo" ("unit-group") (Stanford, 1998, p. 400), rebatizado de "comunidade" ("community") pelos primatólogos ocidentais (Stanford, 1998, p. 400); e o acúmulo de dados de campo sobre chimpanzés começou a somar evidências que levaram os pesquisadores a defender a existência de organização social (Rodseth et al., 1991, p. 222).

$\mathrm{Na}$ década de 1970, foram identificados o impacto de influências ecológicas sobre o comportamento de chimpanzés bem como novos elementos de sua organização coletiva. Defendia-se, então, que os grupos de chimpanzés eram organizados em comunidades defendidas por machos nelas nascidos, onde permaneciam, competiam por ascenção hierárquica e estabeleciam alianças. Ao mesmo tempo, seria comum a migração das fêmeas de seu grupo natal. Isso explicaria o fato, aparente, de os vínculos sociais dos primeiros serem mais fortes que os das últimas (Stanford, 1998, p. 400-401). Posteriormente, Goodall percebeu que as fêmeas também podem possuir alto status e repassá-lo a seus filhotes, fêmeas e machos, o que pode beneficiar a ambos e facilitar a permanência das fêmeas em seu grupo de origem (Goodall, 1999; Hrdy, 2001). O mesmo é válido para o aumento de dados sobre a sociabilidade das fêmeas e sua importância na dinâmica social (Hrdy, 2001; Wrangham et al., 2001).

As décadas de 1980 e 1990 foram, por sua vez, marcadas pela identificação da diversidade de comportamentos entre as populações de chim- 
panzés na África. McGrew (1996) desenvolveu estudos comparativos sobre ferramentas diferentes e seus usos distintos, que chamou de "cultura material”. Böesch, Stanford, Wallis, Mpongo e Goodall registraram variações nos estilos de caça (Stanford, 1998, p. 401). Chapman, White e Wrangham observaram relações entre variabilidade ecológica e forrageamento em diferentes grupos (ibid.).

A partir desse período, e muitos pesquisadores atribuem isso ao aumento do número de mulheres dedicadas à primatologia (Hrdy, 2001; Schapiro, 2002; Strum \& Fedigan, 2000), percebeu-se, também, a variabilidade no comportamento entre sexos e entre populaçôes de chimpanzés (Stanford, 1998, p. 401) relacionada a práticas sexuais, cuidados maternos, vínculos prolongados com filhotes, dinâmica na participação social etc. (Hrdy, 2001). Desde então, novos aspectos do comportamento de chimpanzés têm sido periodicamente relatados.

No final de 1990, McGrew (1996) propôs a substituição das expressões "pré-cultura" e "protocultura", então correntes, pela expressão "cultura" para caracterizar certos aspectos do comportamento de chimpanzés. "Seriam os chimpanzés portadores de cultura?", pergunta-se o autor (McGrew, 1996, p. 79-82) e apresenta registros sobre "inovação", "disseminação" (ocorrência de práticas em subgrupos ou no conjunto de uma população), "padronização" (semelhança entre comportamentos referidos a determinados contextos), "durabilidade", "difusão", "tradição" (enquanto persistência de uma prática de uma geração a outra), "não-subsistência" (ações não exclusivamente destinadas à sobrevivência) e "naturalidade" (condutas reproduzidas pelos chimpanzés que não foram ensinadas ou induzidas por humanos). Diante disso, McGrew entende que todas as condiçóes são atendidas e, portanto, pode-se falar na existência de culturas de chimpanzés (McGrew, 1996, p. 82).

Não que ele afirme que humanos e chimpanzés sejam idênticos, considerando que ambos possuem cultura, mas leva a sério a profunda 
semelhança, lembrando que muitos dos atributos há pouco considerados exclusivamente humanos, como a reprodução de experiências adquiridas por geraçóes sucessivas, possuem inúmeros registros entre chimpanzés (Böesch apud McGrew, 1996, p. 215). Desse modo, McGrew alinha-se às idéias que Goodall tem defendido há décadas: só será possível descobrir as semelhanças entre humanos e chimpanzés quando formos capazes de reconhecer as reais diferenças existentes entre eles (Goodall apud McGrew, 1996, p. 215).

Nessa direção, Chimpanzee Cultures (Wrangham et al., 2001) é um inventário dos fenômenos que os pesquisadores identificam como culturais, com destaque para a reprodução de comportamentos pela via da experiência, o repasse dos mesmos no plano intergeracional (a "tradição") e a variabilidade intergrupal dessas ocorrências, daí a utilização do termo "culturas", no plural, e não "cultura" do chimpanzé.

Ali, as culturas de chimpanzés são concebidas como resultados de um processo (Böesch \& Tomasello, 1998), e a abordagem considerada mais produtiva consiste em investigar seus mecanismos de aprendizado social (Tomasello, 2001, p. 301; McGrew, 1996; Wrangham et al., 2001). Contudo, e apesar da grande adesão, não há consenso absoluto entre os estudiosos do comportamento animal quanto à existência de culturas entre chimpanzés: há os que preferem concentrar-se nas relações sociais (Hrdy, 2001), há os que acham que não existem, ainda, evidências suficientes (Galef, 1992, 1998), e há os que tomam a idéia de cultura num sentido mais antropológico e consideram, portanto, a centralidade da produção simbólica. Estes últimos expressam dúvidas quanto à possibilidade de existência de culturas entre chimpanzés, enfatizando a necessidade de se investigar se eles são capazes de produzir símbolos e, nessa eventualidade, as dificuldades existentes em acessálos e interpretá-los (Tuttle, 2001). 
As pesquisas em primatologia que defendem a existência de culturas entre chimpanzés na África, por sua vez, somam-se, atualmente, a trabalhos realizados sobre chimpanzés cativos em zoológicos, parques ou estações de pesquisa. Até dez anos atrás, pesquisadores de ambos os grupos dividiam-se quanto ao tipo de observação que cada situação proporcionava: o meio original em florestas africanas, hábitats artificiais ou alterados e ambientes controlados por humanos para proporcionar observaçōes sobre indução, simulação, estímulo etc. Segundo Goodall (2001, p. xvii-xviii), tendências mais recentes apontam para o surgimento de um consenso pautado no princípio de que a reunião dessa diversidade de pesquisas pode ampliar a compreensão sobre os chimpanzés. Desde então, têm-se buscado aproximações e realizado trabalhos em conjunto (Wrangham et al., 2001).

Um dos resultados é a formulação coletiva dos estudiosos em favor da existência de culturas de chimpanzés pautadas nos princípios de aquisição, transmissão pela experiência e diversidade do comportamento observado em grupos distintos (Wrangham, 2001a), em que o diálogo entre os pesquisadores expressa-se através do desenvolvimento de estudos comparativos (Heltne, 2001, p. xi) e da padronização dos procedimentos de campo (Goodall, 2001, p. xix), mas, principalmente, expressa a ênfase em fenômenos que eram concebidos como exclusivamente humanos, até a emergência desse tipo de pesquisa. Nesse sentido, saltam aos olhos de qualquer cientista social os temas abordados pelos pesquisadores do comportamento de chimpanzés nas últimas décadas em seus livros e artigos.

Uma lista, incompleta, dos temas abordados, pode ilustrar os rumos que tais pesquisas têm tomado: "culturas de chimpanzés" (Bonner, 2003; Wrangham et al., 2001; Whiten et al. 1999, 2001), "poder" (De Waal, 2000), "cultura material" (McGrew, 1996), "conflito social" (Mason \& 
Mendonza, 1993), "tradiçóes locais" e "transmissão cultural" (Nishida, 1987; Tomasello, 1994), "linguagem" e "comunicação" (Fouts, 1998; Parker \& Gibson, 1994; Tomasello, 2001), relaçōes entre "uso de ferramentas" e "transmissão social de conhecimento" (Tomasello, 1994), "reciprocidade" nas relações chimpanzé/chimpanzé e chimpanzé/humano (Brosnan \& De Waal, 2003), "violência" e "agressividade" (Wrangham $\&$ Peterson, 1996), sem contar balanços e questionamentos relacionados à busca de indícios que permitam, ou não, afirmar se chimpanzés são, ou não, capazes de produzir símbolos (McGrew, 1996; Mithen, 2002; Rumbaugh, Savage-Rumbaugh \& Sevcik, 2001; Tuttle, 2001). Somente reflexões futuras poderão avaliar a legitimidade dos usos desses termos. Enquanto isso, esses pesquisadores avançam como uma força coletiva.

\section{Segundo padrões antropológicos, seres não-humanos podem ser seres culturais?}

Adam Kuper (1999, p. ix-x), ao refletir sobre a centralidade e importância que o termo cultura adquiriu no interior da antropologia cultural americana no pós-guerra, observa a riqueza que as reflexóes produzidas trouxeram para as teorias sobre a cultura e da cultura, inclusive para os meios não-acadêmicos. Ao mesmo tempo, reconhece que especialistas em cultura distribuem-se hoje por um território que não pertence mais exclusivamente à antropologia, tendo-se expandido das ciências sociais para o que se pode chamar de humanidades, cultural studies incluídos. Mais recentemente, o termo cultura surge em argumentos políticos adquirindo sentidos preocupantes (Stolcke, 1995), como o da impossibilidade da integração de imigrantes na Europa devido aos fortes vínculos com suas tradiçōes culturais. Dentre todos, contudo, o uso da cultura 
para explicar comportamentos de seres não-humanos é um dos mais impactantes.

No âmbito da antropologia sociocultural, são amplamente conhecidos os problemas relacionados à idéia de cultura. Kuper (1999) reabriu recentemente o debate, avaliando a permanente inexistência de consenso, entre antropólogos, quanto a uma definição precisa. Além dele, Geertz enfrentou o problema afirmando que há tantas definições possíveis de cultura quanto culturas humanas (Geertz, 1978).

De fato, nas ciências sociais, é possível encontrar, hoje, um amplo espectro de posições. Das críticas ao uso indiscriminado da noção de cultura, por entender que uma expressão tão generalizante, ao referir-se a tudo, esvazia-se e não explica coisa alguma, aos preocupados em reavaliar seus usos no interior da antropologia (Borofsky et al., 2001), até aqueles que defendem sua viabilidade e vitalidade (Brumann, 1999).

O consenso entre antropólogos, produtores da idéia e seus usuários por excelência parece existir quase exclusivamente na aceitação de que uma das maiores dificuldades para a adoção de parâmetros está, justamente, na imensa pluralidade de manifestações culturais humanas. Isso implica que a ênfase na relevância das especificidades culturais dificulta a elaboração de explicações universais.

Ao mesmo tempo em que variabilidade intergrupal e transmissão são palavras-chave nas concepções de antropólogos e etólogos, ambas não possuem o mesmo significado para cada disciplina e operam segundo paradigmas profundamente distintos. Antropologia e etologia utilizam critérios coincidentes para reconhecer a existência de cultura, mas possuem concepções distintas do fenômeno e, do ponto de vista metodológico, operam distintamente.

Mesmo que a importância das relações de parentesco e aliança, das relaçôes econômicas e de poder seja muito maior para a antropologia social que para a antropologia cultural, e apesar do papel secundário da 
cultura nos domínios da antropologia social (Kuper, 1999) e de sua tão aclamada imprecisão (Kuper, 1999; Geertz, 1978), a idéia de cultura é, ainda, um dos fatores generalizáveis da identidade dos antropólogos, em sua vivência da disciplina. Fatores como o papel da vida social na construção da cultura, dado que ela nunca é concebida como inata, seu papel mediador nas relações dos humanos entre si e com a natureza, e a importância dos símbolos em sua reprodução, tidos como os maiores responsáveis pela produção da variabilidade cultural, possuem pesos diferentes, mas são amplamente aceitos tanto por antropólogos culturais quanto por antropólogos sociais.

Os etólogos que estudam chimpanzés e aderiram à idéia de cultura, por sua vez, também não a concebem independentemente dos processos da vida coletiva e da experiência, daquilo que poderíamos chamar de domínio social (Böesch \& Tomasello, 1998; De Waal, 2001b; Fragaszy, 2003; Heltne, 2001). Adotam, contudo, definiçōes muito mais restritas do que as correntes na antropologia. Bonner (1983, p. 14), por exemplo, afirma que cultura é algo distinto da herança genética na medida em que corresponde à "transferência de informação por meios comportamentais, sobretudo pelo processo de ensino e aprendizagem" (Bonner, 1983, p. 14), acumulando-se nas formas de tradição e conhecimento.

Assim, cultura, para os etólogos, é uma definição funcional aplicável a um conjunto de fenômenos forjados pela experiência de alguns animais, no caso aqui, os chimpanzés. São eles: catação (grooming), cognição, comunicação, conflitos, cuidado parental, forrageamento, práticas sexuais, posturas corporais, produção e uso de ferramentas, relações entre mães e filhotes e entre irmãos, produção de status e hierarquia. Cada um é minuciosamente registrado, mas, em sua categoria, aparece isolado com relação às outras. Esse tipo de dado, ao mesmo tempo em que facilita comparações entre grupos e entre espécies distintas de primatas não-humanos, dificulta o estabelecimento de inter-relações 
entre cada comportamento e a produção coletiva de relações no interior do grupo. Em outras palavras, está ausente a noção de totalidade.

Particularmente com relação ao grooming, há duas observações a fazer: ele é considerado um comportamento social típico da espécie que apresenta diversidade (Marchant et al., 2002; McGrew, 1992; McGrew et al., 2001). Evidentemente tal concepção está muito distante das ciências sociais, para as quais os comportamentos sociais são produtos da experiência ao mesmo tempo em que não há distinções relevantes entre sociedade e cultura, exceto para a antropologia cultural. Ao mesmo tempo, vale destacar a identificação de variações no grooming (Marchant et al., 2002; McGrew, 1992; McGrew et al., 2001; Nakamura \& Uehara, 2004), que é justamente um dos argumentos para atribuir caráter cultural a um conjunto de comportamentos de chimpanzés. Esse é um problema que os primatólogos precisarão enfrentar.

A idéia de cultura para os etólogos assenta-se sobre um pressuposto de universalidade que não está restrito à humanidade, e a idéia de "tradição" (Fragaszy, 2003; Nishida, 1987) tem sido usada como um poderoso mediador, recentemente assimilado, mas cada vez mais constante nas abordagens. A influência da tradição no repasse de comportamentos tem sido estendida a outros grandes símios além dos chimpanzés, como os bonobos (Stanford, 1998), gorilas e orangotangos (Schaik, 2001), e a outros macacos, como os do gênero Cebus (Perry \& Mason, 2003; Perry et al., 2003; Visalberghi \& McGrew, 1997), e os cetáceos (Rendell \& Whitehead, 2001).

Por outro lado, o registro antropológico sobre culturas humanas é necessariamente um registro etnográfico. Ele se assenta sobre o pressuposto da possibilidade de reprodução da totalidade de determinada sociedade ou cultura, a partir da estratégia teórico-metodológica adotada, selecionando, a partir do convívio intenso produzido pelo trabalho de campo, aspectos da vida coletiva que possuam sentidos simbólicos e 
estejam articulados no interior daquele grupo. O texto etnográfico deve, portanto, ser um modo de produzir o efeito que melhor permita o acesso do leitor àquele ethos. De acordo com diferentes correntes da antropologia, essa "produção de sentidos" pode discernir, diluir ou enfatizar o papel do antropólogo no processo (Geertz, 1978; Goldman, 2001; Ingold, 1996a; Malinowski, 1978; Oliveira, 1996, 1997).

\section{O problema da produção de significados}

A ausência desse "princípio de totalidade" na apresentação e análise de resultados sobre o comportamento de chimpanzés, que assumem a existência de "culturas entre chimpanzé", pode ser explorada por, pelo menos, dois ângulos. O primeiro refere-se ao procedimento metodológico, que sustenta a validade da análise de fenômenos isolados, ou ao reconhecimento de que um fenômeno geral (ou total) equivale sempre à soma de suas partes. Assim, a organização do material coletado em unidades isoladas, como cuidado materno, ecologia, ferramentas, forrageamento etc., seria decorrência de uma opção metodológica. São raros os casos em que os primatólogos estabelecem relações efetivas entre esses diferentes campos e a dinâmica coletiva do grupo, como nos trabalhos de Goodall e em trabalhos mais recentes que buscam rebater esse tipo de crítica, como os de Marchant, Böesch e Hohman (2002).

O segundo é de outra ordem, pois opera com a hipótese de que a vida coletiva dos chimpanzés seja segmentada ou, ao menos, pareça assim, se comparada à vida humana em sociedade. Nesse caso, os fenômenos não seriam isolados por manipulação metodológica do pesquisador, mas seriam manifestos em campos sem comunicação. Ou seja, o uso de ferramentas para pescar cupins, por exemplo, não estaria relacionado à vida sexual que seria, por sua vez, independente da preferência por de- 
terminado fruto. A catação, nesse sentido, estaria restrita à vida social e não possuiria ramificações em aspectos técnicos do comportamento como a construção de ninhos.

Essas cogitações sustentam-se nas hipóteses do arqueólogo Steven Mithen (2002), que reconhece a possibilidade de existência de tradições entre grupos de chimpanzés, ou variabilidade, com relação por exemplo ao uso de instrumentos ou ferramentas, por admitir que as " $\mathrm{di}$ ferenças (entre grupos distintos) não podem ser explicadas apenas por argumentos genéticos ou ecológicos" (p. 122). Contudo, observa que a passagem da existência de "tradição" para a reprodução de "cultura" em seres não-humanos provavelmente não seja algo tão simples.

Segundo o autor, as "tradições" em grandes símios são profundamente distintas das culturas humanas na medida em que a variabilidade cultural corresponde a expressões singulares manifestas em dimensões da vida social, tais como a arte, a linguagem, o parentesco, a mitologia, a religião, a tecnologia etc., encontráveis em todas as populações. Contrariamente, a variabilidade identificada entre grupos de chimpanzés corresponderia predominantemente à presença ou ausência de determinada prática ou fenômeno e não a modos diversos de expressão numa mesma dimensão da vida. Os etólogos poderiam apresentar o contraargumento de que a catação, os fortes vínculos entre a mãe e sua prole e o uso de ferramentas, por exemplo, são encontráveis em todos os grupos e manifestam variabilidade intergrupal, aspecto que será analisado em outra oportunidade.

$\mathrm{O}$ argumento central de Mithen consiste na defesa de que, enquanto nos humanos, os diferentes domínios da mente - social, lingüístico, técnico e naturalista - estão plenamente integrados, possibilitando o deslocamento de elementos e conhecimento de um a outro, e permitindo a emergência de um pensamento simbólico, o mesmo não ocorre entre chimpanzés e teria tido manifestação apenas germinal entre nossos 
antepassados hominídeos. Ou seja, enquanto seres humanos podem transpor o conhecimento naturalista que possuem sobre animais, incorporando-os a seu universo simbólico e lingüístico (mitologia), social (parentesco, totemismo) e técnico (importação de conhecimento naturalístico, social e lingüístico em favor da produção de cultura material), o mesmo não ocorreria entre os grandes símios. Neles, cada um desses domínios mentais estaria isolado dos outros (Mithen, 2002, p. 117-45).

Assim a diferença entre a mente do chimpanzé e a mente humana não seria apenas de grau, como consolidado pela tradição darwinista, mas sim arquitetônica ou estrutural (id., p. 137-42). Daí os domínios de sua vida coletiva existiriam isoladamente, exatamente como se expressam nos registros dos pesquisadores.

Neste ponto pode-se perguntar se a ausência de integração entre os diversos aspectos do comportamento dos chimpanzés seria, por si só, um limite para lhes aplicar a idéia de "cultura", ou se a dimensão simbólica seria um pré-requisito para a existência das culturas dos chimpanzés, como ocorre com as culturas humanas (Tuttle, 2001). Para explorar essa questão, é preciso observar o modo pelo qual os etólogos estão tratando problemas relativos aos fenômenos, coletivos ou individuais, que possam estar revestidos de caráter simbólico, no comportamento de chimpanzés.

Tanto para a antropologia social quanto para a cultural, a observação, seja de comportamentos, seja de relações sociais ou fenômenos culturais, assenta-se sobre os princípios de observação, registro e apreensão da vida social e/ou da cultura, de um lado, e o da interpretação disso tudo, de outro. No início do século XX, ao mesmo tempo em que enunciava os passos a serem adotados na realização de uma etnografia, Malinowski (1978) alertava ser preciso deixar claras as distinçôes entre o observado, os comentários e as reflexões dos nativos e as interpretações produzidas pelo próprio pesquisador. 
Revista de Antropologia, São Paulo, USP, 2005, v. 48 no 1.

A partir de então, desde seus "pais fundadores" e por meio dos paradigmas funcionalista, funcional-estruturalista, estruturalista, interpretativista, chegando aos pós-modernos e às respostas dos antropólogos sociais contemporâneos a estes, antropólogos têm discutido intensa e profundamente essa questão, avaliando as repercussóes da inter-subjetividade, as possibilidades de acesso do pesquisador aos sentidos dados pelos sujeitos a seus artefatos culturais, a porosidade ou opacidade das fronteiras entre culturas, o caráter, bem como os limites das interpretaçóes feitas pelo antropólogo quando registra e analisa a alteridade a partir do trabalho etnográfico (cf. Kuper, 1999; Geertz, 1978, 1991; Oliveira, 1996, 1988; Rapchan, 2002).

Ora, se ao tratar de seres humanos, cujas existências são conformadas por códigos traduzíveis pela língua, os antropólogos enfrentam inúmeros problemas no que se refere ao acesso aos sentidos da cultura decorrentes de diferenças de linguagem, vivência e atribuição de significados a símbolos e acontecimentos, o que não dizer quando o problema é dirigido às situações de pesquisa sobre chimpanzés? Em resumo, como aponta Ades (1997), coloca-se o problema das dimensóes e de tipos de consciência, da consciência animal e do acesso a elas.

As barreiras de linguagem e as possibilidades, ou impossibilidades, de comunicação entre humanos e chimpanzés constituem-se, provavelmente, em um dos grandes desafios para acessar as culturas dos chimpanzés, caso existam, e a história de Washoe pode ajudar a pensar sobre o assunto. Fouts (1998), ao dar continuidade ao experimento pioneiro do casal Gardner, que recusou a hipótese de incapacidade do uso de linguagem e procurou ensinar a ALS (Linguagem Americana de Sinais) a chimpanzés, tornou-se um dos pioneiros nesse campo. Washoe, uma chimpanzé órfã, adotada pelo grupo de pesquisadores e socializada por humanos, entre humanos e num meio reproduzido a partir de uma cultura humana, tornou-se o ícone dessa história. Os registros de Fouts e 
sua equipe sobre o modo como Washoe se comunica e o tipo de relação estabelecida entre ambos são surpreendentes. Ao ler $O$ parente mais próximo (1998), tem-se a forte sensação de que a interação entre ambos é possível.

O problema é que, em seus hábitats originais, chimpanzés não usam ALS para se comunicar com os pesquisadores. Por outro lado, o uso da ALS por chimpanzés integra-se ao conjunto do que Cavalli-Sforza (2001, p. 59) chama de "linguagem artificial". Segundo ele, gorilas e chimpanzés podem aprender a usar um léxico de 300 a 400 palavras. Um ser humano médio, em comparação, possui um vocabulário dez a vinte vezes maior. Segundo Cavalli-Sforza, grandes símios podem aprender usar símbolos para comunicar coisas simples, mas só são capazes de entender o que eles significam quando mediados por "linguagens artificiais" instrumentalizadas pelos pesquisadores.

Há quem diga que a catação, traduzível também pelo brasileiríssimo cafuné, prática social importantíssima, à qual os chimpanzés dedicam aproximadamente $30 \%$ de todo seu tempo, e fator fundamental para o estabelecimento de relações e alianças (De Waal, 2000), expressão de sentimentos (Goodall, 1991) e resolução de conflitos, funcionaria como uma espécie de linguagem social (Mithen, 2002), além de assumir variações de grupo a grupo (McGrew, Marchant, Scott \& Tutin, 2001), mas, ao que parece, essas observações são ainda inconclusivas.

Cheney e Seyfarth (1990, p. 175-83) procuraram identificar, em primatas não-humanos, interações entre produção de sons e expressão, colocando em foco não somente a comunicação vocal, mas também os sentidos dados à vocalização. Apresentam, por fim, um sumário em que procuram associar representaçôes mentais e relações sociais às vocalizações para, então, avaliar aspectos sociais e não-sociais da inteligência e buscar refletir sobre "como os macacos vêem o mundo". Parker e Gibson (1994), num estudo comparativo sobre "linguagem" e inteligência em 
macacos e grandes símios, organizaram uma coletânea cujo foco são as relações entre inteligência social e comunicação, bem como a manifestação de suas habilidades classificatórias e numéricas.

Na mesma direção, trabalhos como os de Rumbaugh, Savage-Rumbaugh e Sevcik (2001) procuram observar, na história das pesquisas dedicadas ao ensino de linguagem de sinais a grandes símios, a existência de indícios relacionados à compreensão e produção de expressões próprias por parte dos chimpanzés. Tomasello (2001, p. 306-309) registrou aspectos da comunicação gestual em chimpanzés que vivem em seus hábitats originais. Em todos esses trabalhos, os limites parecem ser os mesmos: eles apresentam ricos indícios nas observações sobre indivíduos, mas pequenos avanços no que se refere à produção simbólica e coletiva de sentidos.

Ainda no plano da reflexão sobre os sentidos, Ades (1997) indica que o tratamento da complexa questão da consciência animal solicita avaliações de suas múltiplas implicações quanto à adoção de metodologia e apreensão do complexo fenômeno em questão. Conforme o autor, os procedimentos adotados pela etologia para a abordagem da consciência animal possuem três dimensóes: as traduções perceptuais, as analogias antropomórficas e o uso de critérios comportamentais, e é evidente que, como em qualquer disciplina, aí se encontram suas possibilidades e seus limites (Ades, 1997, p. 129).

Ades (1997, p. 133-4) defende a existência de dois tipos de consciência, uma delas tipicamente humana. A abordagem da consciência animal, por sua vez, precisa enfrentar as dificuldades relativas à tradução perceptual entre os seres humanos e as outras espécies (Ades, 1997, p. 135-37) que perpassa, ainda, as profundas diferenças de comunicação entre o pesquisador e os animais. Por essas razões, segundo Ades, se há possibilidade de se produzir conhecimento sobre outra espécie, este será, necessariamente, produto de uma construção (ibid., p. 133). 
Em que medida o cientista "humaniza" aqueles que pesquisa, por estratégia, pela busca de similaridades a partir de comparaçôes ou pela classificação dos chimpanzés através de um sistema de pensamento que caracteriza e adjetiva elementos de conjuntos a partir de observaçóes e atribuiçôes de características derivadas de associaçōes simbólicas (Ades, 1997; Lévi-Strauss, 1989b, 1988; Mitchell \& Hamm,1997; Mithen, 2002)? Isso compromete o saber produzido ou lhe revela facetas? Como seria possível acessar as consciências dos chimpanzés senão por meio de experimentos que implicam o aprendizado de linguagens para comunicação? Ou, por outro lado, e considerando a existência da possibilidade de comunicação não-verbal entre humanos e chimpanzés, quanto há de subjetividade na interpretação dos pesquisadores para esses casos?

Sistemas de classificação são humanos e universais, produzidos tanto por populaçôes indígenas quanto por comunidades científicas, como já apontou Lévi-Strauss (1989b), porque pensar e classificar são atributos humanos, e eles não se restringem ao mundo sensível, mas abarcam também o universo dos símbolos e mitos, das abstraçóes, das categorias e dos conceitos. Cavalli-Sforza (2001, p. 28) parece concordar com essa assertiva, ao indicar que humanos, sejam botânicos ou !Kung, possuem compulsão pela classificação e usam sua linguagem e seus parâmetros culturais para produzir distinções sutis entre objetos, diferentemente dos outros animais.

Contudo, ainda segundo Cavalli-Sforza (2001, p. 28), chimpanzés também são capazes de classificar folhas e frutos em comestíveis e nãocomestíveis e repassam isso a seus filhotes, sendo mesmo capazes de alterar as classificaçóes, segundo seu apetite e oferta de alimentos, sem deixar de prestar atenção na possível toxicidade dos elementos. Aliás, o leque de sabores conhecido e consumido por chimpanzés em hábitats originais é bastante extenso, conforme registrado em pesquisa de Nishida, Ohigashi e Koshimizu (2000). No entanto, vale observar que 
essa pesquisa não considerou um aspecto óbvio para qualquer antropólogo: as influências culturais sobre a classificação de sabores, especialmente porque os dados são resultado também da degustação pelos primatólogos do que foi consumido pelos chimpanzés.

Outras pesquisas têm, ainda, identificado a possibilidade de chimpanzés reconhecerem e atribuírem individualidades a outros de sua espécie (Hooff, 2001, p. 270-71), capacidade que permitiria, por exemplo, a reprodução de atitudes baseadas em cálculo, planejamento, cooperação e reciprocidade na manipulação social, desde que aprendidas, imitadas e/ou ensinadas (id., p. 271-75).

Em trabalho dirigido exclusivamente à questão da cognição em chimpanzés, Tomasello e Call (1997) abordam elementos relacionados ao conhecimento que chimpanzés obtém do mundo físico e do mundo social. No mundo físico, os pesquisadores identificaram capacidades relativas à busca de objetos escondidos e sua manipulação, ao uso de ferramentas, ao entendimento de relações de causalidade, ao discernimento acerca de características e categorias, além de capacidade de percepção de quantidades. Quanto ao mundo social, os autores apontam a existência de um aprendizado que possibilita a participação ativa em coalizões e alianças, reciprocidade e troca, além de cooperação para solução de problemas. Por fim, identificam a adoção de estratégias sociais e de comunicação, que incluem gestos, vocalização e comunicação com seres humanos.

Contudo, a pergunta permanece: esses indícios são suficientes para se afirmar a existência de culturas entre chimpanzés? Apesar dos dados acima mencionados apresentarem referências a interações entre chimpanzés que podem sugerir, em alguma medida, a existência de fenômenos coletivos, Galef (1998) argumenta que as dificuldades em aceitar a existência de culturas de chimpanzés enraizam-se nos aspectos relacionados à transmissão do conhecimento adquirido com a experiência. 
Segundo o autor, os registros disponíveis referem-se a habilidades individuais em observar e imitar ou facilitar a observação de outros para que reproduzam ações, o que não permite, satisfatoriamente, a transposição dos comportamentos individuais para os coletivos, comprometendo a constituição de um princípio de conduta válido para o grupo, pois os dados referem-se a comportamentos singulares reproduzidos por indivíduos, repassados a partir desses para aqueles com os quais estabelecem relações. Ou seja, segundo Galef, os dados não são convincentes enquanto expressóes de fenômenos coletivos, apesar de serem manifestaçôes individuais, reproduzidos no interior de subgrupos, definidos a partir de critérios como sexo, idade ou status.

Enfrentar o problema das mediações entre o comportamento individual e os sentidos coletivos talvez implique, para os estudiosos do comportamento de chimpanzés, seguir as sugestôes de Tuttle (2001, p. 407-408), ou seja, estudar o que a antropologia sociocultural produziu, desde a Segunda Guerra Mundial, em suas discussóes acerca do que é cultura, em vez de insistir exclusivamente nos resultados das pesquisas empíricas sobre o comportamento de primatas não-humanos, permanecendo isolados dos debates desenvolvidos no interior das ciências sociais.

É inegável que as abordagens, as reflexōes e os dados sobre o comportamento de chimpanzés são surpreendentes, e ainda há muito o que se discutir pois se, de um lado, apontam para a possibilidade dessas descobertas recentes abalarem estruturas e convicçôes nas ciências humanas, por outro, talvez, os cientistas sociais tenham muito a contribuir no entendimento do que os cientistas naturais perseguem: os símbolos, os fenômenos coletivos e seus sentidos. 


\section{Para a conclusão, um conjunto de questões}

Os estudos sobre comportamento animal, particularmente dos grandes símios, estabeleceram nas últimas décadas um efervescente plano de reflexão para as biociências e para as ciências sociais. Aliás, há muito o que pensar sobre o fato de bonobos ou chimpanzés provocarem mais as ciências sociais do que baleias ou elefantes, mas isso merece uma discussão própria, em outra ocasião.

As biociências precisarão responder à questão se o comportamento coletivo animal ou individual, que tenha fundamento coletivo, pode ser satisfatoriamente abordado apenas através dos próprios procedimentos de pesquisa ou necessitarão dos subsídios das ciências sociais, particularmente da antropologia, para enfrentar os novos problemas. Uma pequena lista contempla a aceitação ou a recusa das reflexôes já produzidas pela antropologia sobre o problema da cultura (Tuttle, 2001), o tipo singular de objetividade, próprio das ciências sociais, construído em bases interativas e subjetivas, considerando que pesquisas sobre comportamento animal são pesquisas que implicam relações humanos/animais (Corbey, 1995) e o problema da produção de significados por seres não-humanos (Mithen, 2002). Primatólogos, como McGrew (1992) buscam algumas referências em antropólogos culturais como Alfred Kröeber e Ruth Benedict. Será suficiente?

Outra questão central, de base conceitual, tem implicações na reflexão sobre qual é a teoria de cultura adotada pela primatologia em que, por exemplo, se deve abordar as relaçōes entre "cultural" e "social" quando se trata de comportamento animal. É plenamente satisfatório pensar que o social é típico da espécie e o cultural apresenta variabilidade, submete-se às tradições e é próprio de cada grupo? A cognição é um pontochave e precisará ser muito explorada. 
As ciências sociais, particularmente a antropologia, precisarão enfrentar problemas tais como o questionamento das definições de humano e da singularidade humana nas bases que têm sido reproduzidas desde o início do século XX. Não há mais consenso acerca de que os seres humanos sejam os únicos a desenvolver vida coletiva complexa, produzir cultura, lutar por status e poder, reconhecer seus semelhantes e repassar seus conhecimentos às geraçôes futuras. Ao mesmo tempo, a animalização do humano, a identificação entre os vínculos coletivos de certas espécies e sua condição biológica (Dunbar, 2003), e a possibilidade de identificação do momento evolutivo da emergência do significado na condição humana (Mithen, 2002) constituem-se em grandes questões.

O desafio posto por essa configuração dessas disciplinas implicará a produção de novas fronteiras para o humano, para suas alteridades e para a produção de conhecimento.

\section{Notas}

1 Gostaria de agradecer às valiosas contribuições e sugestões que recebi de Alexandre Locci Martins, César Ades, Eduardo Ottoni, Patrícia Izar, Renato da Silva Queiroz, Rui Murrieta e Walter Neves. Cada um deles dispôs-se a discutir especificamente este trabalho comigo ou trouxe, em ocasióes diversas, contribuições às reflexôes apontadas aqui. Fico grata, também, aos dois pareceristas anônimos da Revista de Antropologia por suas observaçóes e sugestões. Este artigo foi produzido graças ao Plano de Capacitação Docente da Universidade Estadual de Maringá (UEM), que possibilitou meu afastamento das atividades docentes para o desenvolvimento da pesquisa de pós-doutorado, entre março de 2004 e março de 2005. 
Revista de Antropologia, São Paulo, USP, 2005, v. 48 No 1.

\section{Bibliografia}

ADES, C.

1997 "O morcego, outros bichos e a questão da consciência animal", Psicologia USP, São Paulo, vol. 8(2): 129-57.

ALVARD, M. S.

2003 "The Adaptative Nature of Culture", Evolutionary Anthropology, 12: 136-49.

ASQUITH, P. J.

1995 "Of Monkeys and Men: Cultural Views in Japan and the West", in CORBEY, R. \& THEUNISSEN, B. (eds.), Ape, Man, Apeman: Changing Views since 1600, Leiden, Dept. of Prehistory, Leiden University, p. 309-18.

BARKOW et. al.

1992 The Adapted Mind, Oxford, Oxford University Press.

BATESON, P.

2002 “The Corpse of a Wearisome Debate”, Science, vol. 297, Sept., p. 2.212-3, $<$ www.sciencemag.org $>$.

BLANC, M.

1975 Os herdeiros de Darwin, São Paulo, Página Aberta.

BLANCAERT, C.

1995 "La question du singe et l'ordre des primates à la Societé d'Anthropologie de Paris (1865-1870), in CORBEY, R. \& THEYNISSEN, B. (eds.) Ape, man, apeman: Changing Views since 1600, Leiden, Dept. of Prehistory, Leiden University, p. 117-37.

BOAS, F.

1940 Race, language and culture, New York, The McMillan Company.

BÖESCH, C. \& TOMASELLO, M.

1998 "Chimpanzee and human cultures", Current Anthropology, vol. 39(5): 591-614. 
BONNER, J. T.

1983 A evolução da cultura nos animais, Rio de Janeiro, Zahar.

BOROFSKY, R.; BARTH, F.; SHWEDER, R. A.; RODSETH, L. \& STOLZENBERG, N. M. 2001 "WHEN: a conversation about culture", American Anthropologist, 103(2): 423-46.

BROSNAN, S. F. \& DE WAAL, F. B. M.

2003 "Monkeys reject inequal pay", Nature, 425, Sept. 18, p. 297-99.

BRUMANN, C.

1999 "Writing for culture: why a successful concept should not be discarded", Chicago, The University of Chicago Press, Current Anthropology, vol. 40, Supplement, p. S1-S27.

BUNING, T. C.

1995 "What apes teach us about ethics", in CORBEY, R. \& THEYNISSEN, B. (eds.), Ape, man, apeman: changing views since 1600, Leiden, Dept. of Prehistory, Leiden University.

CAVALIERI, P. \& SINGER, P.

1995 "The great ape project", in CORBEY, R. \& THEYNISSEN, B. (eds.), Ape, man, apeman: changing views since 1600, Leiden, Dept. of Prehistory, Leiden University.

CAVALLI-SFORZA, L. L.

2001 Genes, peoples and languages, London, Penguin Books.

CHAZAN, M.

1995 "The meaning of Homo sapiens", in CORBEY, R. \& THEYNISSEN, B. (eds.), Ape, man, apeman: changing views since 1600, Leiden, Dept. of Prehistory, Leiden University, p. 229-38.

CHENEY, D. L. \& SEYFARTH, R. M.

1990 How monkeys see the world, Chicago, University of Chicago Press.

COMAS, J. (ed.)

1970 Raça e ciência I, São Paulo, Perspectiva. 
CORBEY, R.

1995 "Introduction: missing links, or the ape's place in nature", in CORBEY, R. \& THEYNISSEN, B. (eds.), Ape, man, apeman: changing views since 1600, Leiden, Dept. of Prehistory, Leiden University, p. 1-10.

CORBEY, R. \& THEYNISSEN, B. (eds.)

1995 Ape, man, apeman: changing views since 1600, Leiden, Dept. of Prehistory, Leiden University.

CROCKETT, C. et al.

"A psychological well-being program for managing environmental enrichment and behavior issues in a colony of research primates", American Journal of Primatology. Program and Abstracts of the 22th Annual Meeting of the American Society of Primatologists, New Orleans, LA, p. 46.

DARWIN, C.

The origin of species, Hertfordshire, Wordsworth Editions.

2001

A expressão das emoções no homem e nos animais, São Paulo, Companhia das Letras.

DAWKINS, R.

2001

O gene egoísta, Belo Horizonte, Itatiaia.

DE VORE, I. (ed.)

1965 Primate behavior: field studies of monkeys and apes, New York, Holt, Rinehart and Winston.

DE WAAL, F. B. M.

2000

Chimpanzee politics: power and sex among apes, Baltimore, The Johns Hopkins University Press.

$2001 b \quad$ "Chimpanzee's adaptative potencial: a comparison of social life under captive and wild conditions", in WRANGHAM, R. et. al. (eds.), Chimpanzee cultures, Cambridge, Havard Univeristy Press/The Chicago Academy of Sciences.

DESCOLA, P.

1992

"Societies of nature and nature of society", in KUPER, A. (ed.), Conceptualizing society, London \& New York, Routledge. 
DESCOLA, P.

2001 "Construting natures: symbolic ecology and social practice", in DESCOLA, P. \& PÁLSSON, G. (eds.), Nature and society: anthropological perspectives, New York, Routledge.

DOUGHERTY, F.

1995 "Missing link, chain of being, ape and man in the enlightenment: the argument of the naturalists", in CORBEY, R. \& THEUNISSEN, B. (eds.) Ape, man, apeman: changing views since 1600, Leiden, Dept. of Prehistory, Leiden University, p. 63-70.

DUKELOW, R. W.

1999 "Invited editorial: reflections on a century of primatology", American Journal of Primatology, 49: 129-32.

DUNBAR, R. I. M.

2003 "The social brain: mind, language, and society in evolutionary perspective", Annual Review of Anthropology, 32: 163-81.

DURHAM, E. R.

2003 "Chimpanzés também amam: a linguagem das emoções na ordem dos primatas", Revista de Antropologia, vol. 45(1): 85-154.

FOLADORI, G.

2000 "O comportamento humano em relação a seu ambiente, à luz das teorias biológicas da evolução", Acta Scientiarum 22(2): 327-35, Maringá, Ed. UEM.

FOLEY, R.

1993 Apenas mais uma espécie única, São Paulo, Edusp.

FOSSEY, D.

1983 Gorillas in the mist, Houghton Mifflin Cy.

FOUTS, O. \& MILLS, S. T.

1998 O parente mais próximo. O que os chimpanzés me ensinaram sobre quem somos, Rio de Janeiro, Objetiva. 
Revista de Antropologia, São Paulo, USP, 2005, v. 48 No 1.

FRAGASZY, D. 2003

"Making space for traditions", Evolutionary Anthropology, 12: 61-70.

GALEF, B.

1992

1998

"The question of animal culture", Human Nature, vol. 3: 157-78.

Commentaries for BOESCH, C. \& TOMASELLO, M., "Chimpanzee and human cultures”, Current Anthropology, vol. 39(5): 591-614.

GEERTZ, C.

1978 A interpretação das culturas, Rio de Janeiro, Zahar.

GOLDMAN, M.(ed.)

2001 Alguma antropologia, Rio de Janeiro, Relume-Dumará.

GOODALL, J.

1965

1991 Uma janela para a vida: 30 anos com os chimpanzés da Tanzânia, Rio de Janeiro, Zahar.

1999 "The genomic record of humankind's evolutionary roots", American Journal of Human Genetics, 64: 32-39.

2000 In the shadow of man, New York, Mariner Books.

2001 "Foreword", in WRANGHAM, R. W. et al. (eds.), Chimpanzee cultures, Chicago, Harvard University Press/Chicago Academy of Sciences.

GOULD, S. J.

1999 Darwin e os grandes enigmas da vida, São Paulo, Martins Fontes.

HELTNE, P. G. 2001

"Preface", in WRANGHAM, R. et al. (eds.), Chimpanzee cultures, Cambridge, Harvard University Press/The Chicago Academy of Sciences.

HENRICH, J. \& McELREATH, R.

2003

“The Evolution of Cultural Evolution”, Evolutionary Anthropology, 12: 123-35. 
HOOFF, J. Van

2001

"Understanding chimpanzee understanding", in WRANGHAM, R. W. et al. (eds.), Chimpanzee cultures, Chicago, Harvard University Press/Chicago Academy of Sciences.

HRDY, S. B.

2001

Mãe natureza, Rio de Janeiro, Campus.

INGOLD, T. (ed.)

1996a Key debates in anthropology, London/New York, Routledge.

INGOLD, T.

1995

"People like us': the concept of the anatomically modern human", in CORBEY, R. \& Theynissen, B. (eds.), Ape, man, apeman: changing views since 1600, Leiden, Dept. of Prehistory, Leiden University, p. 241-62.

1996b "Debate: human worlds are culturally constructed", Against the motion (1), in INGOLD, T. (ed.), Key debates in anthropology, London/New York, Routledge.

JAHME, C. 2001

Beauty and the beasts: woman, ape and evolution, London.

JOULIAN, F. 1996

"Comparing chimpanzee and early hominid techniques: some contributions to cultural and cognitive questions", in MELLARS, P. A. \& GIBSON, K. A. (eds.), Chimpanzee Cultures, McDonald Institute for Archaeological Research.

KUPER, A.

The invention of primitive society: transformation of an illusion, London/New York, Routledge.

1999

Culture: the anthropologists' account, Cambridge, Harvard University Press.

2000

"If memes are the answer, what is the question?", in AUNGER, R. (ed.), Darwinising culture: the status of memetics as a science, Oxford, Oxford University Press.

LALAND, K. \& HOPPITT, W.

"Do animals have culture?", Evolutionary Anthropology, 12: 150-9. 
Revista de Antropologia, São Paulo, USP, 2005, v. 48 no 1.

LAURENT, G.

1995 "Lorigine animale de l'homme au XIXe siècle", in CORBEY, R. \& Theynissen,

B. (eds.), Ape, man, apeman: changing views since 1600, Leiden, Dept. of Prehistory, Leiden University, p. 157-71.

LÉVI-STRAUSS, C.

1970 "Raça e história", in COMAS, J. (ed.), Raça e ciência I, São Paulo, Perspectiva. 1988 Las estructuras elementales del parentesco, Barcelona, Paidós.

1989a "A noção de arcaísmo em etnologia", in Antropologia Estrutural, Rio de Janeiro, Tempo Brasileiro.

1989b O pensamento selvagem, Campinas, Papirus.

LEWIS, H. S.

2001 "Boas, Darwin, science, and anthropology", Current Anthropology, 42(3): 381-406.

\section{LIEBERMAN, L.}

1989

"A discipline divided: acceptance of human sociobiological concepts in anthropology", Current Anthropology, 30(5): 676-82.

LINTON, R.

1936 The study of man, New York, Appleton-Century-Crofts.

LORENZ, K.

1995 Os fundamentos da etologia, São Paulo, Editora da Unesp.

MASSENZIO, M.

2001 "An interview with Claude Lévi-Strauss", Current Anthropology, 42(3): 419-25.

McGREW, W. C.

1992 Chimpanzee material culture, Cambridge, Cambridge University Press.

1998 "Culture in nonhuman primates?", Annual Review of Anthropology, 27: 301-28.

2001a "Overiew: diversity in social relations", in WRANGHAM, R. et. al. (eds.), Chimpanzee cultures, Cambridge, Havard Univeristy Press/The Chicago Academy of Sciences.

$2001 \mathrm{~b}$ "Tools compared: the material of culture", in WRANGHAM, R. et. al. (eds.), Chimpanzee cultures, Cambridge, Havard Univeristy Press/The Chicago Academy of Sciences. 
McGREW, W. C.; MARCHANT, L. F.; SCOTT, S. E. \& TUTIN, C. E. G.

2001 "Intergroup differences in a social custom of wild chimpanzees: the grooming hand-clasp of the Mahale Mountains", Chicago, The University of Chicago Press, Current Anthropology, 42(1): 148-53.

MALINOWSKI, B.

1978 Argonautas do Pacifico Ocidental. Um relato do empreendimento e das aventuras dos nativos nos Arquipélagos da Nova Guiné-Melanésia, São Paulo, Abril Cultural.

MARCHANT, L.; BÖESCH, C. \& HOHMANN, G. (eds.)

2002 Behavioural diversity in chimpanzees and Bonobos, Cambridge, Cambridge University Press.

MASON, W. A. \& MENDOZA, S. P. (eds.)

1993 Primate social conflict, Albany, State University of New York Press.

MAUSS, M.

1974 Antropologia e sociologia, 2 vols., São Paulo, Epu/Edusp.

MITCHELL, R. W. \& HAMM, M.

1997 "The interpretation of animal psychology: anthropomorphism or behavior reading?", Behaviour, 134: 173-204.

MITHEN, $\mathrm{S}$.

2002

A pré-história da mente: Uma busca das origens da arte, da religiāo e da ciência, São Paulo, Editora da Unesp.

MORGAN, L. H.

1946 La sociedad primitiva, Buenos Aires, Lautaro.

NAKAMURA, M. \& UEHARA, $S$.

2004 "Proximate factors of different types of grooming hand-clasp in mahale chimpanzees: implications for chimpanzee social customs", Current Anthropology, 45: 108-14. 
Revista de Antropologia, São Paulo, USP, 2005, v. 48 No 1.

NASH, R.

1995

“Tyson's pygmie: the orang-outang and augustan 'Satyr"”, in CORBEY, R. \& Theynissen, B. (eds.), Ape, man, apeman: changing views since 1600, Leiden, Dept. of Prehistory, Leiden University, p. 51-62.

NISHIDA, T.

1987

"Local traditions and cultural transmission", in SMUTS, B. B.; CHENEY, D.

L.; SEYFARTH, R. M.; WRANGHAM, R. W. \& STRUHSAKER, T. T., Primate societies, Chicago, University of Chicago Press.

2001

"Afterword. Review of recent findings on mahale chimpanzees: implications and future research directions", in WRANGHAM, R. W. et. al.(eds.), Chimpanzee cultures, Chicago, Harvard University Press/Chicago Academy of Sciences.

NISHIDA, T.; OHIGASHI, H. \& KOSHIMIZU, K.

2000 "Tastes of chimpanzee plant foods", Chicago, The University of Chicago Press, Current Anthropology, 41(3): 431-38.

\section{OHNUKI-TIERNEY, E.}

1995 "Representations of the monkey (Saru) in japanese culture", in CORBEY, T. \& THEYNISSEN, B. (eds.), Ape, man, apeman: changing views since 1600, Leiden, Dept. of Prehistory, Leiden University.

OLIVEIRA, R. C. de.

1988 "A categoria de (des)ordem e a pós-modernidade na antropologia", Anuário Antropológico/86, Brasília/Rio de Janeiro, Editora UnB/Tempo Brasileiro.

1996 "O trabalho antropológico: olhar, ouvir, escrever", Revista de Antropologia, vol. 39.

1997 Sobre o pensamento antropológico, Rio de Janeiro, Biblioteca Tempo Universitário.

PARKER, S. T. \& GIBSON, K. R. (eds.)

1994 "Language" and intelligence in monkeys and apes, Cambridge, Cambridge University Press.

PAVELKA, M. S. M.

2002 "Change versus improvement over time and our place in nature", Current Anthropology, vol. 43, supplement, aug.-oct, p. S37-S44. 
PERRY, S. \& MANSON, J. H.

2003 "Traditions in monkeys", Evolutionary Primatology, 12: 71-81.

PERRY, S.; PANGER, M.; ROSE, L.; BAKER, M.; GROS-LUIS, J.; JACK, K.; MACKINNON, K.; MANSON, J.; FEDIGAN, L. \& PYLE, K.

"Traditions in wild white-faced capuchin monkeys", in FRAGASZY, D. \& PERRY, S. (eds), The biology of traditions: models and evidence, New York, Cambridge University Press.

PIETERSE, J. N.

"Apes imagined: the political ecology of animal symbolism", in CORBEY, R. \& THEYNISSEN, B. (eds.), Ape, man, apeman: changing views since 1600, Leiden, Dept. of Prehistory, Leiden University, p. 341-50.

POLIAKOV, L.

O mito ariano, São Paulo, Perspectiva/Edusp.

QUEIROZ, R. da S.

1998 "Nascemos para matar? Notas sobre o comportamento agressivo", Revista de Etologia, São Paulo, número especial, p. 86-92.

RAPCHAN, E. S.

2002

"Relativismo epistêmico, relativismo antropológico: reflexões sobre a produção do pensamento no âmbito das construções da antropologia", Maringá, Acta Scientiarum, vol. 24(1): 261-70.

2004

"Os parentes de nossos parentes: um ensaio sobre a sociedade e as culturas dos chimpanzés sob uma perspectiva antropológica”, Revista de Etologia, vol. 6(2): 33-49.

RENDELL, R. \& WHITEHEAD, H.

2001 "Culture in whales and dolphins", Bahavioral and Brain Sciences, 24: 309-82.

REYNOLDS, V. \& REYNOLDS, F.

1965 "Chimpanzees of the Bundongo Forest", in DE VORE, I. (ed.), Primate behavior: field studies of monkeys and apes, New York, Holt, Rinehart and Winston. 
Revista de Antropologia, São Paulo, USP, 2005, v. 48 No 1.

RODMAN, P. S.

1999 "Whither primatology? The place of primates in contemporary anthropology", Annual Review of Anthropology, 28: 311-39.

RODSETH, L.; WRANGHAM, R. W.; HARRIGAN, A. M. \& SMUTS, B. S.

1991 "The human community as a primate society", Current Anthropology, 32(3): 221-54.

ROOIJAKKERS, G.

1995 "European apelore in popular prints, 17th-19th centuries", in CORBEY, R. \& THEYNISSEN, B. (eds.), Ape, man, apeman: changing views since 1600, Dept. Prehistory, Leiden, Leiden University, p. 327-35.

RUMBAUGH, D. M.; SAVAGE-RUMBAUGH, E. S. \& SEVCIK, R. A.

2001 "Biobehavioral roots of language: a comparative perspective of chimpanzee, child and culture", in WRANGHAM, R. W. et. al. (eds.), Chimpanzee cultures, Chicago, Harvard University Press/Chicago Academy of Sciences.

RUSE, M.

1983 Sociobiologia: senso ou contrasenso?, São Paulo/Belo Horizonte, Edusp/Itatiaia.

SAID, E. W.

1990

Orientalismo, São Paulo, Companhia das Letras.

1995

Imperialismo e cultura, São Paulo, Companhia das Letras.

SCHAIK, C. P. VAN

2001 "Orangutan traditions and their implications", in Program and Abstracts of The 24th Annual Meeting of The American Society of Primatologists, Savannah, Georgia, p. 102.

SCHAIK, C. P. Van; ANCRENAZ, E.; BORGEN, G.; GALDIKAS, B.; KNOTT, C. D.; SINGLETON, I.; SUZUKI, A. UTAMI, S. S. \& MERRILL, M.

2003 "Orangutan cultures and the evolution of material culture", Science, 299: 102-15. 
SCHAPIRO, S. J.

"Characteristics of the membership of the American Society of Primatologists: 2001", American Journal of Primatology. Program and Abstracts of the 25th Annual Meeting of the American Society of Primatologists, 1-4 jun., vol. 57, Supplement 1.

SCHWARCZ, L. K. M.

1993 O espetáculo das raças, São Paulo, Companhia das Letras.

SKRZYPCZAK, J.-F.

1996 O inato e o adquirido. Desigualdades "naturais", desigualdades sociais, Lisboa, Instituto Jean Piaget.

SPENCER, F. 1995

"Pithekos to Pithecanthropus: an abbreviated review of changing scientific views on the relationship of the anthropoid apes to homo", in CORBEY, R. \& THEYNISSEN, B. (eds.), Ape, man, apeman: changing views since 1600, Leiden, Dept. of Prehistory, Leiden University, p. 13-22.

SPERBER, D. 1985 "Anthropology \& psychology: towards an epidemiology of representantions", Man, 20(2).

1996 Explaining culture: a naturalistic approach, London, Blackwell.

SPRUIT, I. 1995

"On declaring non-human primate rights: an approach to primate protection", in CORBEY, R. \& THEYNISSEN, B. (eds.), Ape, man, apeman: changing views since 1600, Leiden, Dept. of Prehistory, Leiden University.

STANFORD, C. B.

1998 "The social behavior of chimpanzees and bonobos", Chicago, The University of Chicago Press, Current Anthropology, 39: 399-420.

STOCKING Jr., G. W.

1997 Race, culture and evolution, Chicago, University of Chicago Press. 
STOLCKE, V.

1995 "Talking culture: new boundaries, new rhethorics of exclusion in Europe", Current Anthropology, 36: 1-24.

STRUM, S. C. \& FEDIGAN, L. M.(eds.)

2000 Primate encounters: models of science, gender, and society, Chicago, Chicago University Press.

TOMASELLO, M.

$1994 \quad$ "Cultural transmission in the tool use and communicatory signaling of chimpanzees?", in PARKER, S. T. \& GIBSON, K. R. (eds.), "Language” and intelligence in monkeys and apes, Cambridge, Cambridge University Press.

2001 "The question of chimpanzee culture", in WRANGHAM, R. et al. (eds.), Chimpanzee cultures, Cambridge, Harvard University Press/The Chicago Academy of Sciences.

TOMASELLO, M. \& CALL, J.

1997 Primate cognition, New York/Oxford, Oxford University Press.

TOOBY, J. \& COSMIDES, L.

1992 "The psychological foundations of culture", in BARKOW, J. et al. (eds.), The adapted mind, Oxford, Oxford University Presses.

TUTTLE, R. H.

2001

"On culture and traditional chimpanzees", Current Anthropology, 42(3): 407-8.

TYLOR, E. P.

1912 Antropologia: introducción al estudio del hombre y de la civilización, Madrid, Daniel Jorro.

VAYDA, A. P.

1996 Methods and explanations in the study of human actions and their environmental effects, Cifor/WWF Special Publication <www.cifor.org> consultado em 3/11/2005.

VISALBERGHI, E. \& MCGREW, W.

1997 "Cebus meets Pan”, International Journal of Primatology, 18: 677-81. 
WILSON, E. O.

Sociobiology: the new synthesis, Cambridge, Harvard University Press.

WHITEN, A. et al.

1999 "Cultures in chimpanzees", Nature, 399: 682-85.

2001 "Charting cultural variation in chimpanzees", Behaviour, 138: 1.481-516.

WRANGHAM, R. et al. (eds.)

2001 Chimpanzee cultures, Cambridge, Harvard Univeristy Press/The Chicago Academy of Sciences.

WRANGHAM, R.

2001a "Overview. Ecology, diversity, culture", in WRANGHAM, R. et al. (eds.), Chimpanzee cultures, Cambridge, Harvard Univeristy Press/The Chicago Academy of Sciences.

WRANGHAM, R. \& PETERSON, D.

1996 O macho demoniaco, Rio de Janeiro, Objetiva.

WRANGHAM, R. W. \& HUFFMAN, M. A.

1994 "Diversity of medicinal plant use by chimpanzees in the wild", in WRANGHAM, R. W. et al. (eds.), Chimpanzee cultures, Cambridge, Harvard University Press/ The Chicago Academy of Sciences.

ABSTRACT: The text proposes a reflection about the growing use of culture's idea, in the last years, to define some aspects of chimpanzees behavior, considering its characteristics and contexts, as well as the questions that this kind of procedure poses to the Social Sciences toward an Anthropology of Ideas and Knowledge's .

KEY-WORDS: chimpanzee cultures, darwinism, ethology, evolution/adaptation, nature/nurture relations.

Aceito em outubro de 2005. 